\title{
EDITORIAL
}

\section{CMI: Highlights in last three years}

\author{
Zhi-Qing Hu
}

Cellular \& Molecular Immunology (2016) 13, 709-710; doi:10.1038/cmi.2016.44; published online 29 August 2016

Cellular \& Molecular Immunology (CMI) is a 13-year-old 'young' journal. In 2009, we were delighted to obtain our first impact factor score of 2.765. Since then, the impact factor of $C M I$ has increased (Figure 1). Based on the 2015 Journal Citation Report released by Thomson Reuters, $C M I$ has reached a new impact factor milestone with a score of 5.193 (5.018 without journal self-cites) and is ranked \#31 out of 150 journals in the Immunology Category. In the 'Impact Factor Era,' nothing makes journal editors happier than seeing this delightful breakthrough. Here, we would like to share our happiness with our contributors. On behalf of the editors of CMI, Drs Xuetao Cao, Yongjun Liu, Zhigang Tian, our guest editors and the editorial board members, we express our sincere thanks to all of the authors, peer reviewers and readers.

In a retrospective review of the papers published in the last three years (2014-2016) that contributed to immunology worldwide and our readership, we found six papers on viral hepatitic immunology, including topics ranging from HBV receptor NTCP, ${ }_{1}$ HBVpersistent mouse models and their immunologic tolerance, ${ }^{2}$ new perspectives on the immune tolerance to chronic clinical HBV infection, ${ }^{3}$ the roles of neutrophils ${ }^{4}$ and NK cells ${ }^{5}$ in HBV infection, and the role of chemokines

Microbiology and Immunology, Showa University School of Medicine, Tokyo 142-8555, Japan

E-mail: zqhu@med.showa-u.ac.jp

Received: 29 June 2016; Accepted: 30 June 2016

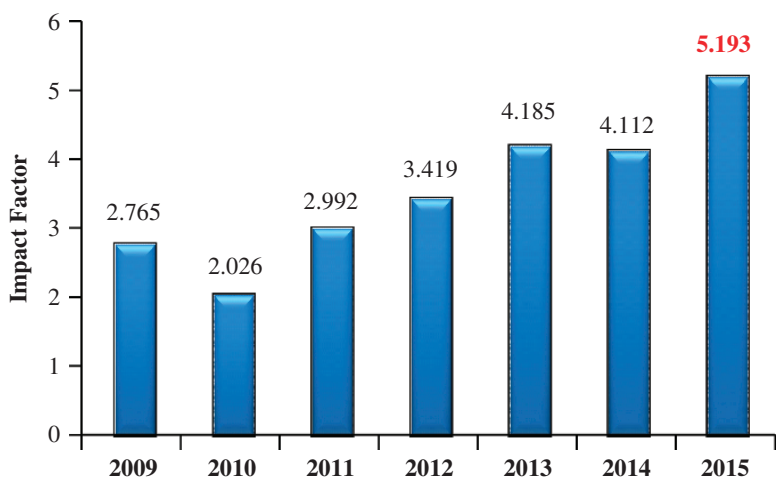

Figure 1 Changes in impact factor score of CMI between 2009 and 2015.

in $\mathrm{HCV}$ infection, ${ }^{6}$ because these topics were attractive to our readers and investigators. We predict that the immunological study of viral hepatitis, a worldwide health problem, will continue to be important and sought-after research for many more decades.

Additionally, eight highly cited papers focused on reproductive immunology, including the physiological and pathological activation of immune cells in preterm labor, ${ }^{7}$ the interaction of extracellular vesicles with the maternal immune system during reproduction, ${ }^{8}$ the integrative roles of chemokines, ${ }^{9}$ MicroRNAs, ${ }^{10}$ NK cells, ${ }^{11}$ DCs $^{12}$ and Th17 cells ${ }^{13,14}$ at the maternal-fetal interface during pregnancy, and testicular immune privilege. ${ }^{15}$ The ongoing investigation of the unique immunological features of mammalian reproduction is likely to continue to attract increasing research and readership.

The interaction of iPSCs with the immune system has been investigated by many researchers, and two papers have focused on the potential immunogenicity of iPSCs ${ }^{16,17}$ and their applications in immunotherapy, ${ }^{17}$ with both subjects likely to garner increased interest as their novel field of research develops.

We hope that more immunologists will contribute their best papers to CMI, among which we will organize more papers with common interesting into special issues to shape CMI's features. We will continue to do our best to provide superior services to our authors and high-quality papers in immunology to our readers.

\section{CONFLICT OF INTEREST}

The author declares no conflict of interest.

1 Li H, Zhuang Q, Wang Y, Zhang T, Zhao J, Zhang $Y$ et al. HBV life cycle is restricted in mouse hepatocytes expressing human NTCP. Cell Mol Immunol 2014; 11: 175-183. 
2 Yang D, Liu L, Zhu D, Peng H, Su L, Fu YX et al. A mouse model for HBV immunotolerance and immunotherapy. Cell Mol Immunol 2014; 11: 71-78.

3 Bertoletti A, Kennedy PT. The immune tolerant phase of chronic HBV infection: new perspectives on an old concept. Cell Mol Immunol 2015; 12: 258-263.

4 Xu R, Huang H, Zhang Z, Wang FS. The role of neutrophils in the development of liver diseases. Cell Mol Immunol 2014; 11: 224-231.

5 Sun C, Sun H, Zhang C, Tian Z. NK cell receptor imbalance and NK cell dysfunction in HBV infection and hepatocellular carcinoma. Cell Mol Immunol 2015; 12 . 292-302.

6 Fahey S, Dempsey E, Long A. The role of chemokines in acute and chronic hepatitis $C$ infection. Cell Mol Immunol 2014; 11: 25-40.

7 Gomez-Lopez N, St Louis D, Lehr MA Sanchez-Rodriguez EN, Arenas-Hernandez M.
Immune cells in term and preterm labor. Cell Mol Immunol 2014; 11: 571-581.

8 Tannetta D, Dragovic R, Alyahyaei Z, Southcombe J. Extracellular vesicles and reproduction-promotion of successful pregnancy. Cell Mol Immunol 2014; 11: 548-563.

9 Du MR, Wang SC, Li DJ. The integrative roles of chemokines at the maternal-fetal interface in early pregnancy. Cell Mol Immunol 2014; 11: 438-448.

10 Bidarimath M, Khalaj K, Wessels JM, Tayade C. MicroRNAs, immune cells and pregnancy. Cell Mol Immunol 2014; 11: 538-547.

11 Rajagopalan S. HLA-G-mediated cell senescence promotes vascular remodeling: implications for reproduction. Cell Mol Immunol 2014; 11: 460-466.

12 Leno-Duran E, Munoz-Fernandez R, Olivares EG, Tirado-Gonzalez I. Liaison between natural killer cells and dendritic cells in human gestation. Cell Mol Immunol 2014; 11: 449-455.
$13 \mathrm{Fu} \mathrm{B}$, Tian Z, Wei $\mathrm{H}$. TH17 cells in human recurrent pregnancy loss and preeclampsia. Cell Mol Immunol 2014; 11 : 564-570.

14 Wu HX, Jin LP, Xu B, Liang SS, Li DJ. Decidual stromal cells recruit Th17 cells into decidua to promote proliferation and invasion of human trophoblast cells by secreting IL-17. Cell Mol Immunol 2014; 11: 253-262.

15 Zhao S, Zhu W, Xue S, Han D. Testicular defense systems: immune privilege and innate immunity. Cell Mol Immunol 2014; 11: 428-437.

16 Fu X. The immunogenicity of cells derived from induced pluripotent stem cells. Cell Mol Immunol 2014; 11: 14-16.

17 Jiang Z, Han Y, Cao X. Induced pluripotent stem cell (iPSCs) and their application in immunotherapy. Cell Mol Immunol 2014; 11: 17-24. 